\title{
Influence of natural and artificial light on structured steel buildings
}

\author{
E.C. Castanheira ${ }^{\text {a,*, H.A. Souza }}{ }^{\text {a }}$, M.Z. Fortes ${ }^{\text {b }}$ \\ a Department of Civil Engineering - Ouro Preto Federal University(UFOP), Brazil \\ ${ }^{\mathrm{b}}$ Department of Electrical Engineering (TEE) - Fluminense Federal University (UFF), Niterói, RJ, Morro do Cruzeiro Campi Ouro Preto Minas Gerais \\ 35400-000, Brazil
}

\section{A R T I C L E I N F O}

\section{Article history:}

Received 24 September 2014

Received in revised form

12 February 2015

Accepted 3 April 2015

Available online 23 April 2015

Keywords:

Natural and artificial lighting

Design guidelines

Energy efficiency

\begin{abstract}
A B S T R A C T
Optimum possible use of natural light is a factor that must be considered in new construction projects. Particularly, construction structuralized in steel needs research that supports the designers in devising proposals. In this work, the author considers references for lighting projects for construction structuralized in steel, using a methodology built from the compilation of several variables that directly interfere in the development of architectural projects both in residential, commercial and/or services buildings. It takes into account the use of all natural light potential and new lamp technologies, which confronts the demands of energy economy that surround the subject of energy consumption reduction in construction focused on environmental sustainability. Some points related to the integration between lighting and architectural projects also are mentioned. To conclude this work, two project guidelines (methodological approaches) for support in the delineation of projects are presented considering three distinct and interconnected approaches: environmental, normative and architectural. The guidelines for the proposals attempt to efficiently handle diverse design aspects that can contribute to more adequate solutions in all sectors that involve creating projects and, executing them. Thinking about the project from a systematic point of view taking into account the contribution of each sector improves project quality.
\end{abstract}

(c) 2015 Elsevier Ltd. All rights reserved.

\section{Contents}

1. Introduction. . . . . . . . . . .

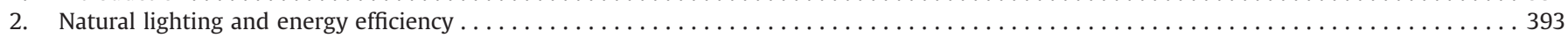

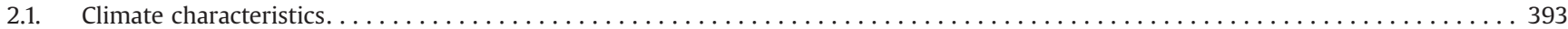

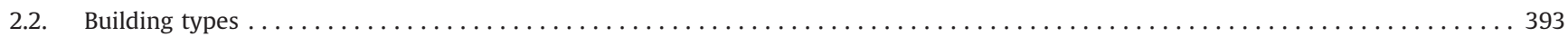

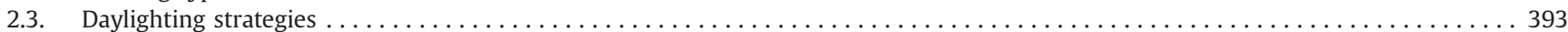

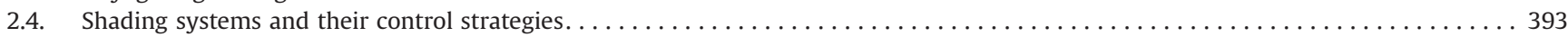

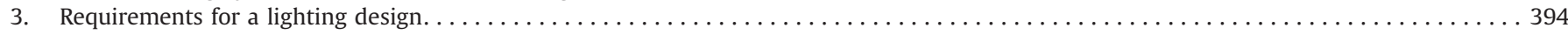

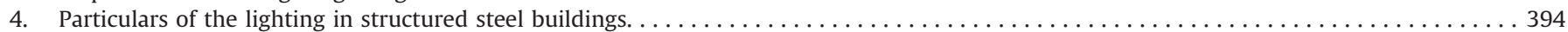

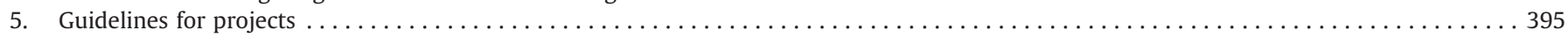

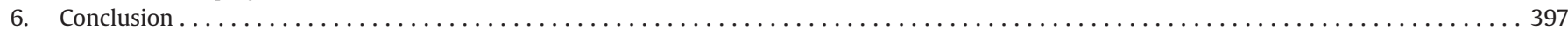

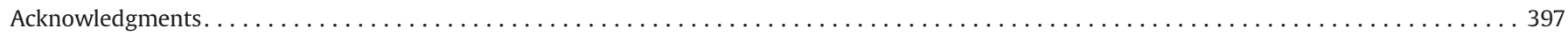

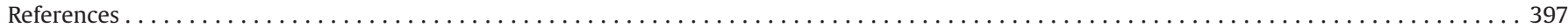

\section{Introduction}

Buildings account for nearly $40 \%$ of global energy consumption and $40 \%$ and $15 \%$ of that are consumed, respectively, by heating,

\footnotetext{
* Corresponding author.

E-mail addresses: eduardocunhacastanheira@gmail.com (E.C. Castanheira), henorster@gmail.com (H.A. Souza), mzf@vm.uff.br (M.Z. Fortes).
}

ventilation and air conditioning (HVAC) and lighting [1]. The use of energy in commercial buildings, for example, is declined, reaching $250 \mathrm{~kW} \mathrm{~h} / \mathrm{m}^{2}$ in 2002.[2].

To know the relation between technologies of light bulbs well, the potential of the natural light and lighting is the initial point so that a lighting project is adjusted to the building's use. The subject of lamps and lighting with revision of the characteristics of some lighting equipment technologies (in special lamps) available on the market is presented in Damelincourt [3]. The impact of the application of electronic lamps in 
buildings is a concern, with considerations regarding product quality. In Fortes et al. [4-6], the authors study compact fluorescent lamps (FLC) available on the Brazilian market tested by a laboratory certifier and the harmonic impacts.

In Brazil, where this work was developed, efficient lighting system projects have begun replacing old projects, a process known as retrofitting, which is argued in detail in Vahl et al. [7] considering technician, economic, and environmental aspects in the project analysis.

The impact of technology in energy building consumption also must be studied when making lighting equipment choices. When commencing a project, an analysis of the lighting and energy efficiency index must be conducted. In Stroker [8], some of these indices are described. Evaluating with good precision the consumption that the construction will have is part of the planning for an efficient and adjusted project; in this context, Stokes et al. [9] present a proposal for evaluation of domestic lighting demand.

The use of control systems and automation in buildings (Building Automation and Control Systems, BACS) and the ecodesign for lighting projects to personalize the environments is also foci of the analysis in the consumption criteria and reuse of natural light. The use of index LENI (Lighting Energy Numeric Indicator) that it is developed in this concept is debated in Parise and Martirano [10]. Another work focused in the control systems with potential analysis of lighting energy savings in office rooms is presented in Roisin et al. [11]. In studies with a focus on reducing consumption in residential sector can highlight the review presented in Pacheco et. al. [12] and Gago et al. [13].

Moreover, Parise and Martirano [14] present a criterion to evaluate the yearly daylight impact on energy performance of internal lighting according to daylight availability. This research team presents the suggestion of a lighting systems certificate involving some specific performance indicators [15].

It is also had that to highlight several research studies related to building certifications. In Brazil, in particular, there is a labeling program for buildings, supervised by the Ministry of Energy, through the Program for Energy Conservation (PROCEL) and the Brazilian Labeling Program (PBE) [16,17]. Worldwide, there are programs with the same focus, and Marshall et al. [18] offer a review of definitions and calculation methodologies. Melo et al. [19] compare the standardization of Brazilian buildings and ASHRAE Standard 90.1 [20] and summarize the equivalence between the standards.

Other interesting researches related to buildings' energy consumption highlighted by the authors of this paper are as follows: influence of the coupling between daylight and artificial lighting on thermal loads [21], an overview about energy building consumption with respect to different building types [22], effects of occupancy and lighting use patterns [23], strategies to reduce energy use for lighting [24], neural network models used in lighting control of LED systems [25] and economic analysis of the daylight-linked on/off lighting control system installed in office buildings considering different numbers of floors and glazing ratio [26].

This paper addresses the main aspects of natural and artificial building lighting design, with special attention given to structured steel buildings and general requirements for energy efficiency and comfort with reduced environmental impact. In this context, guidelines are proposed that encompass three approaches: environmental, architectural and normative aspects. The approaches were compiled from studies, checks, standards and practice of architecture projects development, where these various topics are often considered in the project design.

\section{Natural lighting and energy efficiency}

The main factors influencing the energy efficient use of natural lighting in buildings are the aspects related to the environmental characteristics: knowledge of local area climatic characteristics, the type of building, daylighting strategies (opening solutions incorporated in the building), and types of shading systems and their control strategies. [27] reported that daylighting controls can result in energy savings ranging from $30 \%$ to $77 \%$.

\subsection{Climate characteristics}

One of the main constraints aspects of comfort and energy efficiency in buildings is, of course, the prevailing climate. The natural lighting available in a given location is a function of local latitude, the prevailing weather conditions (particularly the cloudiness of the sky), and the time of day and year. The diverse climates usually have two more seasons to solve complicated thermal conditions and two intermediate periods that have relatively mild conditions most of the time. Brazil's seasons are characterized by a high availability of natural light. These characteristics give the country good potential conditions for the use of natural light throughout the year for illumination of interior spaces; however, this can also leads to the situations of potential thermal discomfort, especially in tropical countries, which imply the need for effective sun protection strategies. It is important to consider the climatic characteristics in the choice of materials for the building. The paper [28] presents these materials assessment in an analysis of the building internal temperature.

\subsection{Building types}

Buildings with higher electricity consumption for lighting have periods of operation that coincide with periods of increased availability of natural light. Practically, all non-residential buildings have significant potential savings in electricity for lighting if investments are made in effectively utilizing natural lighting.

To know and explore the use of natural lighting in new projects or adaptations in existing buildings is also part of the challenges. Some interesting case studies presented in Ref. [29] where a historic building was adapted in the natural light concept use for activities as public library and [30] where computational simulation support lighting analyzes in a Palace.

\subsection{Daylighting strategies}

Among the various fields of environmental comfort and energy efficiency in buildings, natural lighting has higher level relationships and interdependencies with architectural design. The shape, dimensions, and other architectural features of buildings (and particularly those directly related to glazed areas) are the first factor that influence the use of natural light, while defining the image of the building, both from an esthetic, functional and technological point of view. There is, therefore, interest in properly articulating these two aspects from the earliest stages of a project, with the fundamental assumption functionality and the guarantee of good natural lighting inside the various sections of the building. The need to provide the most appropriate lighting levels is a necessary condition, but still insufficient, since there is still a need to ensure the safety and well-being of the occupants, i.e., enjoying a comfortable indoor visual environment and visual contact with the outside, absence of glare, energy efficiency, among others aspects.

\subsection{Shading systems and their control strategies}

It is very significant to influence the effect that shading devices may have on lighting conditions, visual and thermal comfort, and energy consumption (for artificial lighting and air conditioning, for example) in buildings. Shading devices can play several following functions, such as:

- Protection against sunlight. 
- Control and modeling of natural lighting.

- Avoiding obfuscation, concealment, and dimming.

- Ensuring privacy.

- Contact with the outside, among others.

It is possible to identify some important aspects related to the use of shading devices in non-residential buildings and its influence on lighting conditions and energy consumption. Indeed, buildings with potential natural lighting can create many problems in real working situations that result in the dissatisfaction of occupants (the visual and thermal comfort level) and excessive consumption of electricity for lighting. Some of the main reasons for these problems are as follows:

- Improper use of the type of shading device used for the modeling and control of natural light and controlling the dazzle (glare).

- Lack of automation strategies for the control of shading devices. In most buildings, the strategies that predominately offer sun protection clearly avoid the use of natural light. Moreover, in many situations, the lack of upgradeability of these controls/ devices by the occupants also poses an issue.

- Lack of versatility, flexibility, and difficulty in handling (mechanics and location, for example) the manual controls of shading devices that discourage its use.

- Lack of functional planning of interior spaces (location of fixed jobs and the controls of lighting and thermal control systems, etc.).

- Lack of coordination between the architectural strategies, the use of natural light, and control of solar gain.

\section{Requirements for a lighting design}

The lighting design should include quantitative issues, such as the adequacy of illuminance in relation to the tasks to be performed in the environment, and quality, as proper color reproduction and a correct definition of the character of the environment: dynamic or static environment, receptive or distant, intimate or public, stressed, as well as appreciating the qualities of space. This is where the color temperature of the light source becomes important. Thus, it was necessary to include multiple items in the lighting design aspect of the project. Architects, engineers, and designers need to continue to explore and realize the potential in this area that will give the ambience to the interior space [31].

There are studies to develop computing platforms to support impact studies of natural light in energy consumption. In Ref. [32], there is a software example developed in Window Information System (WIS) program and programmed in Matlab and other similar researches in Ref. [33].

It is important to report that an intelligent lighting design is also an economic project, both from the standpoint of initial investment and operating cost, not only for the user but for the whole society. Reducing energy consumption does not mean deprivation of comfort and the benefits that it provides, but entails transformation of losses in a more evolved and rational use of energy resources. In most cases, the elimination of losses requires minimal or no investment and the results are obtained through the awareness of consumers and users. Remember that lighting is for people and not for the building and that good lighting and reducing energy consumption bring significant productivity increases.

Thus, to establish conditions for a project that integrates natural and artificial lighting, the following steps should be completed:

- Study cognitive and symbolic aspects of light attached to the character of the spaces and the cultural and symbolic attributes associated with them.
- Study new lighting technologies, comfort, maintenance, and control commands.

- Survey technical situations relating to the use of natural and artificial lights and compare them with the construction process of buildings in steel structures.

- Elaborate parameters in order to save optics systems, reducing their impacts and generating satisfaction in users. "To develop certain visual activities, our eye requires specific conditions". Basically, the less effort that the eye must make to adapt to environmental conditions, the better it is for the eye [31].

- Set guidelines for energy savings in buildings with natural light (since it avoids undesirable light-thermal loads).

- Set guidelines for esthetic appreciation of architectural work, emphasizing the building and its construction characteristics of both internal spaces-its volume and its insertion into the outer urban landscape;

- Consider and observe the use of daylighting in buildings where various types of activities take place simultaneously in the same space. (A problem may occur as distinct activities require different levels of luminance).

- Evaluate how the architecture and engineering respond and have responded to technology regarding the exploitation of light advances, including the growing need for energy saving.

- Taking advantage of esthetic and functional lighting.

- Selecting artificial light sources that offer a wide range of lamps with different color temperature for use in projects.

- Structural system compatibility with designs of logic, ventilation, sound, hydraulics, among others.

- Designating appropriate fixtures, system maintenance, the deployment of funds and maintenance of cost, and glare control.

- Ensure that the lighting system rely on fixtures, ballasts, and lamps of high efficiency; taking into account the characteristics of the lamps, appliances and adopted types of artificial lighting, thereby reducing heat emissions of appliances and light bulbs.

- Proper distribution of electrical circuits.

- Exploitation of architectural features, such as brise, canopies, eaves as filters of incident light.

- Observation of decorative components that include chandelier lighting, sconces, table lamps, lampshades, and external lighting.

- Observation of auxiliary lighting components that include projectors, electrified rails and wall washers.

\section{Particulars of the lighting in structured steel buildings}

The steel constructions more frequently create new constructive attitudes and different approaches since the possibilities of using the transparency that generates the highest amount of natural light, are often a feature of these projects that get the slenderness of the structure and lighter locks. This characteristic of panel locks consisting of translucent parts creates, on the other hand, the loss of reflective surfaces of artificial light. The guts of the building are highly exposed and vulnerable to receive and spread light both inside and outside to the inside to the outside at night. Artificial light then goes on to have a complementary character in moments where natural light may be insufficient for required or obstacles to privacy and sun protection. One can thus, through controls and strategic positions of lighting design solutions, reduce the period of operation of lighting systems to contribute greatly to the economy in energy consumption. In night periods, the exterior lighting from the local where the building is deployed should be taken into consideration since this contribution can affect the quality and quantity of light required inside the building.

For lighting systems in steel buildings, electrical power rout must seize the various paths of the structure since the shortage of 
panels that can incorporate the electrical pipes might not be enough to incorporate all necessary points.

The technological improvements of the glassmaking industry as well as to other products have brought more freedom, more challenges to projectors, and the chance to make buildings more efficient from the point of view of energy, with facade projects becoming more complex and elaborate. From insulated double glazing (consisting of two glass plates in a frame with an air layer in between), many developments have yielded better thermal properties to glass facades. In Europe, low-e (low emissivity glass) technology was developed, which reduces emissivity and permits entry of a large light quantity. The indicated material to capture ample light consists of metal oxide layers that integrate with glass in industrial processes containing a high-cost vacuum and plasma environment. In an adaptation to the climate of the southern hemisphere, the low-e won a camera solar control results in a solution that also allows the passage of light, and it has reflective characteristics. The low-e solar control presents a reflectivity between $8 \%$ and $10 \%$ and a light transmission between $70 \%$ and $80 \%$. Furthermore, the material can be received to enhance its properties and to impart energy security features. A recent development in this direction is glass with the ability to select the most beneficial solar longwave for lighting comfort.

Thus, lowering environmental impact and improving energy efficiency in buildings becomes important not only to demonstrate clearly how natural lighting can contribute to the rational use of energy in buildings, but also to introduce techniques that enable the designer to ensure efficiency energy to the interior natural lighting.

It is estimated that the use of appropriate architectural standards, materials specifications and energy-efficient products, and the adequacy of criteria for rational designs can enable up to a $60 \%$ reduction in energy consumption of buildings.

\section{Guidelines for projects}

To better understand the preparation process of lighting (natural or artificial) and architectural design that considers natural lighting in a more elaborate way, this paper proposes several steps to follow as shown in Figs. 1 and 2. The guidelines were mounted considering various aspects often used and needed in buildings design.

Initially, one must distinguish what is considered lighting design (artificial or natural). To design artificial lighting considers the solution for illuminating environments from the point of view of meeting the basic requirements of an illumination with the amount of light required to meet the needs of users and the visual esthetic comfort they desire for their space. Many times, the space already exists and providing the space with light constitutes a general solution. The lighting project as its name indicates is a mix of lighting techniques that must complement the entire architectural design. Within this framework, the project considers environmental, normative, and architectural dimensions. The three foci considered can be addressed not necessarily in the sequence described, even having to all the items, since different buildings have different needs. Another aspect to be scored is the importance (weight/degree/value index) that each methodology item can or should be contemplated during the project design.

The first approach (environmental) will consider all aspects of the physical environment that the project will engage and will

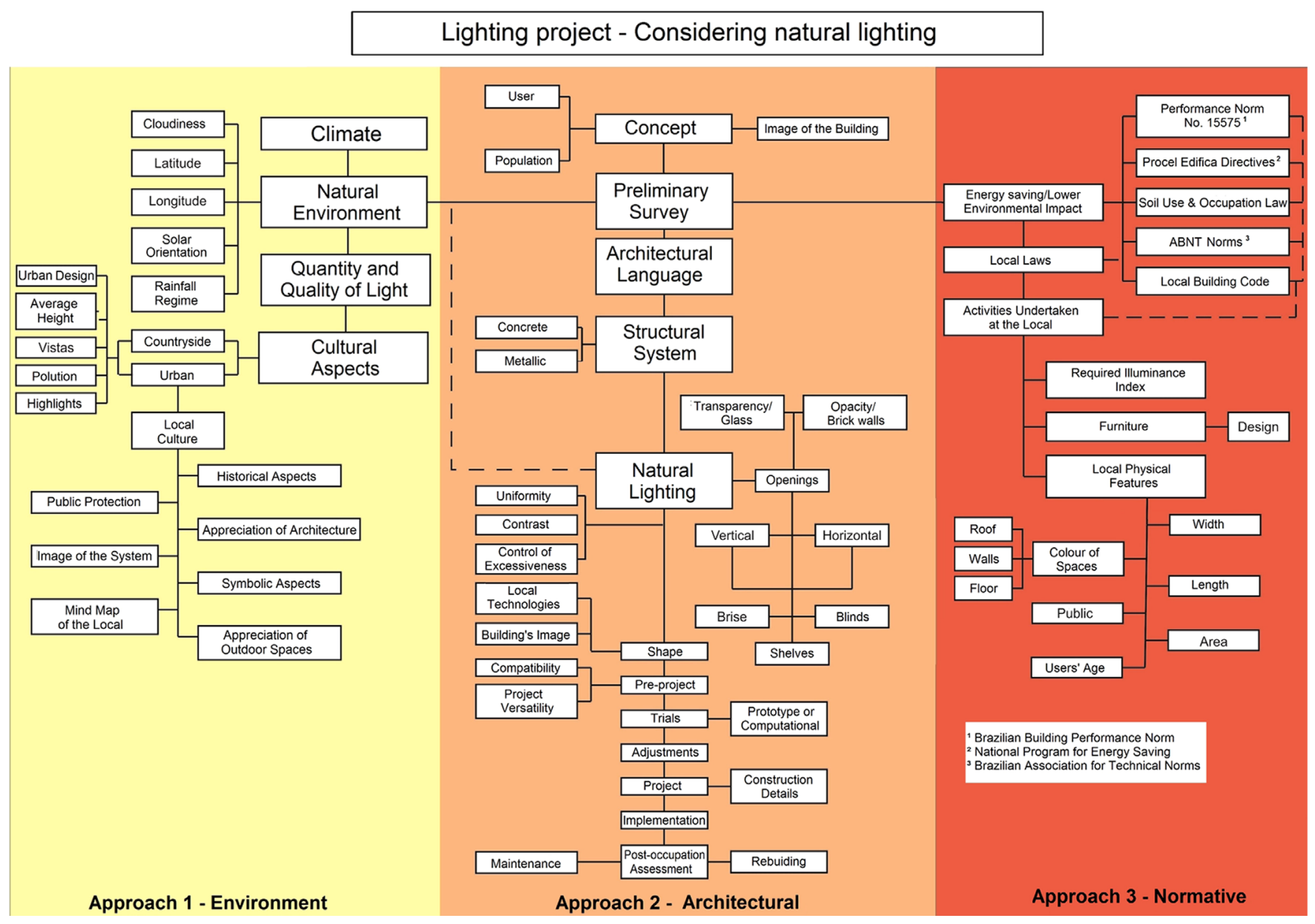

Fig. 1. Guidelines for projects considering natural lighting. 


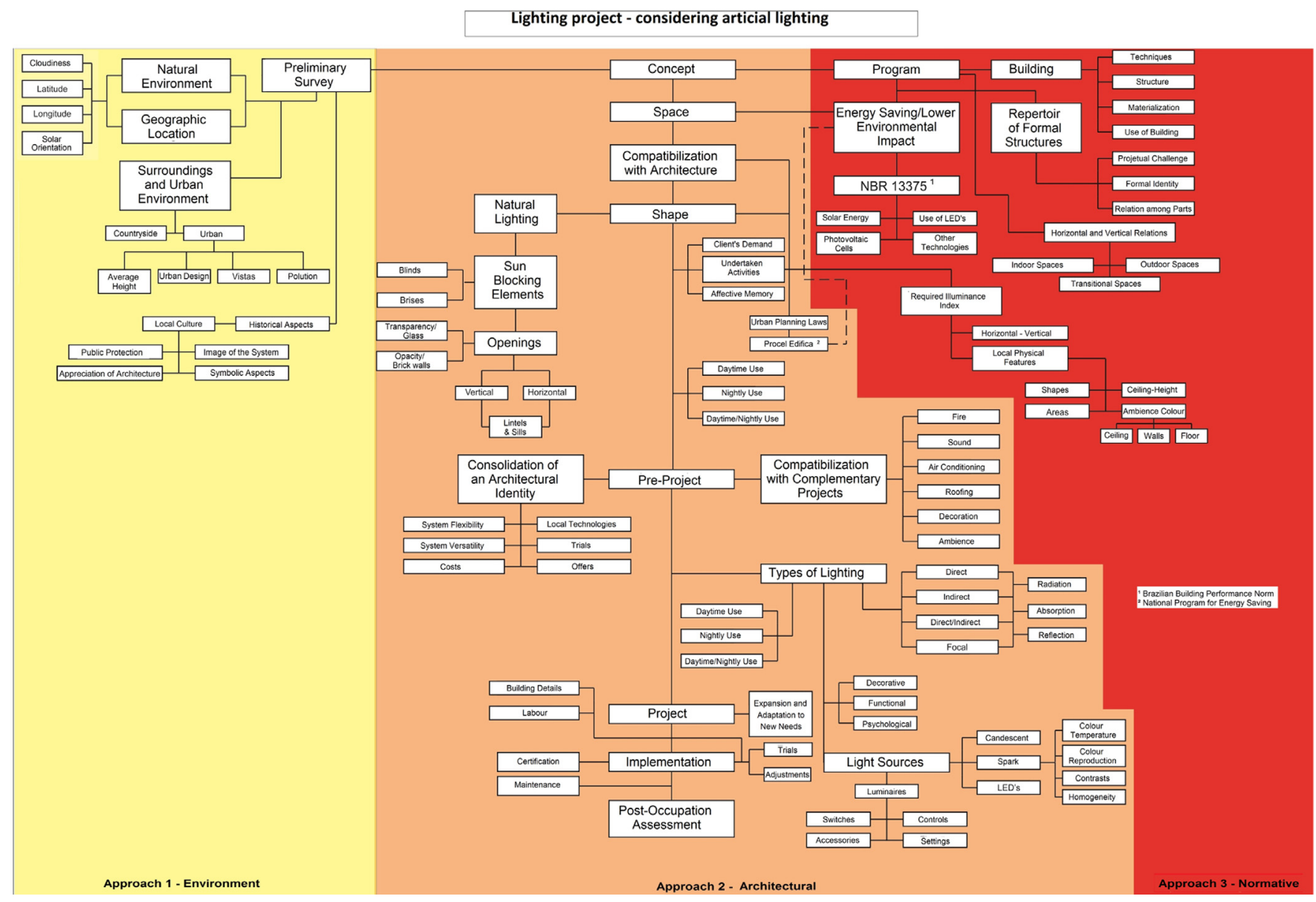

Fig. 2. Guidelines for projects considering artificial lighting.

precede the first design trace. This approach should be discussed by individuals involved in the project (process) still in design. Again, environmental, cultural, and other aspects must be considered.

The second approach (architectural) will bring together the various data previously collected and begin the process of drawing the object. It is believed that the process can be continually reviewed in the two previous approaches to legitimize the ideas and the design (project).

The third approach (normative) will consider all parameters that have been defined by legislation and standards. One should be aware if certain standards/rules revisions and criticisms have merit. As standards and regulations are often generalized, distinct objects must be analyzed under different considerations.

The first approach (environmental) (Fig. 1) for the design of natural lighting will consider all aspects of the physical environment in which the building will be inserted preceding the commencement of the project. This approach should be discussed by all the characters involved in the project (process) still in design. At this time, the protagonist is definitely the environment. $\mathrm{He}$ is going to give guidelines that should be followed in the approach. Cultural considerations are also made since these are aspects that give the specific character (personality) to spaces.

The analysis of the natural environment and geographical location will allow solutions of window openings, views, sun protection, and use of natural light at the best times of day and during all seasons. The environment and the built environment call for an analysis of obstructions, air and visual pollution, noise, and other characteristics that may interfere in the decisionmaking during the project. The image of the building should consider all cultural and historical aspects in order to establish dialogs with local people, preventing visual pollution, unrealistic images of the set and consequently averse of population.

The second approach (architectural) will bring together the various design information architecture collected and begin the process of drawing the object. It is believed that this process is constantly reviewed in the two previous approaches to legitimize the ideas and the design (project). This step is considered mainly the 'language' that the project wants to transmit, its image, esthetic and spatial characteristics, and compatibility with other complementary projects. This stage is the primary field of design and technical representation tools as well as a judicious development of details.

The third approach (normative) for the design of daylighting will consider all parameters that have been defined by legislation and standards. One should be aware if certain rules have merit review and criticism, largely because of the increasing trend of the values and uses of spaces today. As rules and regulations are often generalized, or specific to certain locations, different objects should be analyzed under different aspects because it will safeguard the minimum quantity light in the environment to practice a specific activity. This item is very important since it includes specifics of the design/building locations that mainly protect the lighting quality in quantitative terms, allowing the use of space without compromising the users' health. The ambient colors, the furniture, and other aspects of the space's occupation are also parameters considered for proper sizing of lighting. Another very important aspect is the consideration of the new guidelines and laws considering aspects of energy saving and final use of energy that are currently discussed in several different forums.

The first approach (environmental) (Fig. 2) for the design of artificial lighting takes into account the same guidelines already 
discussed for the design of natural lighting; however, an important aspect of this case is lighting external spaces during night periods and providing security to adjacent spaces. The building also will gain a historical and symbolic, commercial, institutional image and will be references and site reconnaissance. The image of the building wins this evening attribute so that may or may not engage with the surrounding space and be recognized by people. In the historic towns or buildings are not the enlightened have the role of helping to create the nightly mental map. In this item cannot be forgotten the region microclimate and the final use that the building will have. This topic very well discussed in the research by Camuffo et al. [34].

The second approach (architectural) designs for artificial lighting will go beyond the guidelines of the methodology of natural lighting, the ambience of spaces, both from the point of view of classifying spaces with different uses, e.g., esthetic, decorative, etc. In this method, the aspects related to the choice of various types of lighting should be considered: direct, indirect, semi-direct (indirect), fixtures, lamps, color temperatures, construction details, compatibility with the various projects, and of course the initial and operational cost of the system adopted. An example where a part of these considerations are included is a research presented by Rosemann et al. [35] considering cost, new fixtures, lighting index and energy savings analysis.

The third approach (normative) for the design of artificial lighting will consider all parameters that have been defined by law and standards of approach to daylighting design, plus the standards and guidelines for artificially lit spaces. With the increasing use of spaces in the nighttime periods, these conditions of light quality are of utmost importance.

For steel structured buildings, the three distinct approaches (environmental, architectural, and normative) can be described for projects that include natural lighting, artificial lighting and the ideal projects that simultaneously address the two types of situations. It is crucial that the interplay of the various aspects

\section{Conclusion}

This paper presents the main aspects of the natural and artificial lighting design into buildings considering the general framework for the requirements of comfort, energy efficiency with reduced environmental impact, the need for coordination with other areas of the project suitability, and the influence of occupants. This study also highlights the importance of natural light as a fundamental component of designing energy-efficient lighting.

The main characteristic of natural lighting, which distinguishes it from artificial lighting, is its dynamic character associated with temporal variations and variations in cloudy conditions. Traditional methods of performance prediction of daylighting in buildings and the metrics used for its quantification have limitations that do not allow one to take into account, effectively and realistically, the effects of the dynamic characteristics of natural light and in particular those related to the influence of climate. Thus, the context of lowering environmental impact and improving energy efficiency in buildings become important not only to demonstrating clearly how natural lighting can contribute to the rational use of energy in buildings, but also using techniques that enable the designer to ensure that efficiency energy plans are based on interior natural lighting.

It is estimated that the use of appropriate architectural standards, specification of materials and energy-efficient products and the adequacy of criteria for rational designs can enable up to a $60 \%$ reduction in the energy consumption of buildings, giving architects, engineers, and designers the opportunity to explore and realize this potential [36].

Importantly, an intelligent lighting design is also an economic project, both in terms of initial investment and operating cost, not only for the user, but for the whole society. One should remember that conserving energy does not mean reduction of comfort and deprivation of the benefits it provides. Conserving energy implies the transformation from a waste society to a more rational one that carefully considers the use of global resources, especially energy inputs. Examples of this buildings concept are in Arab World Institute in Paris by Jean Nouvel, and Norman Foster designs as: Reichstag Palace in Berlin and $30 \mathrm{St}$. Mary Axe and the London City Hall Buildings in London.

From the perspective of comfort and energy efficiency being desirable for indoor spaces lighting is made, preferably, using natural light should be supplemented by effective and flexible artificial lighting systems, as lighting needs cannot be satisfied only using natural light.

Thus, the use of natural lighting in buildings and, in particular, those with predominantly daytime occupation, can contribute significantly to energy efficiency, visual comfort, and the wellbeing of its occupants.

In this sense, the strategies of natural light should consider the potential gains and heat losses (if any overheating occurs during hot periods, overcooling during cold periods, and heat gains due to the use of artificial lighting), the reduction of energy consumption (to replace artificial lighting and to reduce or eliminate the use of mechanical air conditioning), and also the more subjective benefits for the occupants from the use of natural light instead of artificial light and enjoyment of the view outdoors.

\section{Acknowledgments}

The authors like to acknowledge primarily the Ouro Preto Federal University (UFOP) and Fundação de Amparo a Pesquisa do Estado de Minas Gerais (FAPEMIG).

\section{References}

[1] Sun B, Luh PB, Jia QS, Jiang Z, Wang F, Song C. Building energy management: integrated control of active and passive heating, cooling, lighting, shading, and ventilation systems. IEEE Trans Autom Sci Eng 2013;10:588-602. http://dx.doi. org/10.1109/TASE.2012.2205567.

[2] Bomberg M, Andreas F. The energy conundrum of modern buildings. Front Archit Res 2013;2:500-2. http://dx.doi.org/10.1016/j.foar.2013.09.001.

[3] Damelincourt JJ. Lamps and lighting. Eng Sci Educ J 2000:196-202. http://dx. doi.org/10.1049/esej:20000502.

[4] Fortes MZ, Fragoso AP, Pereira AME, Tavares GM. Analise sobre a qualidade das LFC's disponíveis no mercado Brasileiro. Rev SODEBRAS 2013;8:63-6.

[5] Fortes MZ, Pereira AME, Fragoso AP, Tavares GM. Avaliação das LFC's nos Limites de Tensão do PRODIST. Engevista 2014;16:283-91.

[6] Fassarela JEV, Fortes MZ, Fragoso AP, Tavares GM. Analysis and Suggested solution of power quality problems in lighting laboratory. IEEE Lat Am Trans 2014;12:1019-26. http://dx.doi.org/10.1109/TLA.2014.6893995.

[7] Vahl FP, Campos LMS, Casarotto Filho N. Sustainability constraints in technoeconomic analysis of general lighting retrofits. Energy Build 2013;67:500-7. http://dx.doi.org/10.1016/j.enbuild.2013.08.039.

[8] Stroker JJ. What's the real cost of higher efficiency?. IEEE Indus Appl Mag 2003:32-7. http://dx.doi.org/10.1109/MIA.2003.1195680.

[9] Stokes M, Rylatt M, Lomas K. A simple model of domestic lighting demand. Energy Build 2004;36:103-16. http://dx.doi.org/10.1016/j.enbuild.2003.10.007.

[10] Parise G, Martirano L. Ecodesign of lighting systems. IEEE Indus Appl Mag 2011:14-9. http://dx.doi.org/10.1109/MIAS.2010.939809.

[11] Roisin B, Bodart M, Deneyer A, Herdt PD. Lighting energy savings in offices using different control systems and their real consumption. Energy Build 2008;40:514-23. http://dx.doi.org/10.1016/j.enbuild.2007.04.006.

[12] Pacheco R, Ordóñez J, Martínez G. Energy efficient design of building: a review. Renew Sustain Energy Rev 2012;16:3559-73. http://dx.doi.org/ 10.1016/j.rser.2012.03.045.

[13] Gago EJ, Muneer T, Knez M, Koster H. Natural lights controls and guides in buildings. Energy savings for electrical lighting, reduction of cooling load. Renew Sustain Energy Rev 2015;41:1-13. http://dx.doi.org/10.1016/j.rser.2014.08.002.

[14] Parise G, Martirano L. Daylight impact on energy performance of internal lighting. IEEE Trans Ind Appl 2013;49:242-9. http://dx.doi.org/10.1109/ TIA.2012.2229454.

[15] Parise G, Martirano L, Di Ponio S. Energy performance of interior lighting systems. IEEE Trans Ind Appl 2013;49:2793-801. http://dx.doi.org/10.1109/ TIA.2013.2263114. 
[16] MINISTÉRIO DE MINAS E ENERGIA-BRASIL. Política Nacional de Conservação e Uso Racional de Energia. Lei n 10.295, 17 de outubro de 2001.

[17] INSTITUTO NACIONAL DE METROLOGIA, NORMALIZACÃO E QUALIDADE INDUSTRIAL - INMETRO. RTAC001424: Regulamento Técnico da Qualidade para Eficiência Energética de Edifícios Comerciais, de Serviços e Públicos, Portaria ${ }^{\circ}$ 53, de 27 de fevereiro de, Rio de Janeiro, 2009.

[18] Marszal AJ, Heiselberg P, Bourelle JS, Musall E, Voss K, Sartori I, et al. Zero energy buildings - a review of definitions and calculation methodologies. Energy Build 2011;43:971-9. http://dx.doi.org/10.1016/j.enbuild.2010.12.022.

[19] Melo AP, Sorgato MJ, Lamberts R. Building energy performance assessment: comparison between ASHRAE standard 90.1 and Brazilian regulation. Energy Build 2014;70:372-83. http://dx.doi.org/10.1016/j.enbuild.2013.11.080.

[20] American Society Of Heating, Refrigerating And Air Conditioning Engineers. ANSI/ASHRAE/IES Standard 90.1: energy standard for buildings except lowrise residential buildings, 2013. p. 174.

[21] Franzetti C, Fraisse G, Achard G. Influence of the coupling between daylight and artificial lighting on thermal loads in office buildings. Energy Build 2004;36:117-26. http://dx.doi.org/10.1016/j.enbuild.2003.10.005.

[22] Lombard LP, Ortiz J, Pout C. A review of buildings energy consumption information. Energy Build 2008;40:394-8. http://dx.doi.org/10.1016/j. enbuild.2007.03.007.

[23] Yun GY, Kim H, Kim JT. Effects of occupancy and lighting use patterns on lighting energy consumption. Energy Build 2012;46:152-8. http://dx.doi.org/ 10.1016/j.enbuild.2011.10.034.

[24] Dubois MC, Blomsterberg A. Energy saving potential and strategies for electric lighting in future North European, low energy office buildings: a literature review. Energy Build 2011;43:2572-82. http://dx.doi.org/10.1016/j.enbuild.2011.07.001.

[25] Wang Z, Tan YK. Illumination control of LED systems based on neural network model and energy optimization algorithm. Energy Build 2013;62:514-21. http://dx.doi.org/10.1016/j.enbuild.2013.03.029.
[26] Yang IH, Nam EJ. Economic analysis of the daylight-linked lighting contro system in office buildings. Sol Energy 2010;84:1513-25. http://dx.doi.org/ 10.1016/j.solener.2010.05.014.

[27] Ihm P, Nemri A, Krarti M. Estimation of lighting energy savings from daylighting Build Environ 2009;44:509-14. http://dx.doi.org/10.1016/j.buildenv.2008.04.016.

[28] Sadeghifam AN, Zahraee SM, Meynagh MM, Kiani I. Combined use of design of experiment and dynamic building simulation in assessment of energy efficiency in tropical residential buildings. Energy Build 2015;86:525-33. http://dx.doi.org/10.1016/j.enbuild.2014.10.052.

[29] Balocco C, Calzolari R. Natural light design for an ancient building: a case study. J Cult Hermitage 2008;9:172-8. http://dx.doi.org/10.1016/j.culher.2007.07.007.

[30] Balocco C, Frangioni E. Natural lighting in the hall of two hundred. a proposa for exhibition of its ancient tapestries. J Cult Hermitage 2010;11:113-8. http: //dx.doi.org/10.1016/j.culher.2009.02.005.

[31] PROGRAMA NACIONAL DE CONSERVAÇÃO DE ENERGIA ELÉTRICA _ PROCEL Uso Racional de energia elétrica em edificações. São Paulo, 1992.

[32] Hviid CA, Nielsen TR, Svendsen S. Simple tool to evaluate the impact of daylight on building energy consumption. Sol Energy 2008;82:787-98. http: //dx.doi.org/10.1016/j.solener.2008.03.001.

[33] Nielsen TK. Simple tool to evaluate energy demand and indoor environment in the early stages of building design. Sol Energy 2005;78:73-83. http://dx. doi.org/10.1016/j.solener.2004.06.016.

[34] Camuffo D, Pagan E, Bernardi A, Becherini F. The impact of heating, lighting and people in re-using historical buildings: a case study. J Cult Hermitage 2004;5:409-16. http://dx.doi.org/10.1016/j.culher.2004.01.005.

[35] Rosemann A, Mossman M, Whitehead L. Development of a cost-effective solar illumination system to bring natural light into a building core. Sol Energy 2008;82:302-10. http://dx.doi.org/10.1016/j.solener.2007.09.003.

[36] ASSOCIAÇÃO BRASILEIRA DE NORMAS TÉCNICAS. NBR 15575: Eddifícios habitacionais - Desempenho, Rio de Janeiro, 2013. p. 312. 